\title{
UJI POTENSI ALELOPATI EKSTRAK DAUN MANGGA (Mangifera indica. L.) SEBAGAI BIOHERBISIDA TERHADAP GULMA BABANDOTAN (Ageratum conyzoides L.)
}

\section{POTENTIAL of ALLELOPATHIC POTENTIAL of MANGGA LEAF EXTRACT (Mangifera indica. L.) as BIOHERBISIDE AGAINST BABANDOTAN WEEDS (Ageratum conyzoides L.)}

\author{
Guntoro $^{1)}$, Mhd Yusuf Dibisono'), Anisyah Sinaga ${ }^{1)}$ \\ ${ }^{1)}$ Program Studi Budidaya Perkebunan, Sekolah Tinggi Ilmu Pertanian Agrobisnis \\ Perkebunan (STIP-AP) \\ Jl. Williem Iskandar, Medan 20226 \\ Correspondence author: guntoro@stipap.ac.id
}

\begin{abstract}
ABSTRAK
Penelitian ini bertujuan untuk mengetahui efektivitas dan konsentrasi optimum ekstrak daun mangga (Mangifera indica L.) yang memiliki senyawa fenol yang berfungsi sebagai bioherbisida yang dapat menghambat pertumbuhan gulma Babandotan (Ageratum conyzoides). Penelitian ini dilakukan di rumah kaca STIPAP dari bulan April hingga Mei 2019. Metode yang digunakan adalah Desain Acak Lengkap Non-Faktorial. Variabel yang diamati adalah tinggi gulma, panjang akar gulma, bobot basah gulma, dan bobot kering gulma. Hasil penelitian ini menunjukkan bahwa senyawa alelokimia ekstrak daun mangga $60 \%$ merupakan konsentrasi yang efektif dan merupakan bioherbisida alternatif dalam mengendalikan pertumbuhan gulma.
\end{abstract}

Kata kunci : Bioherbisida, Mortalitas, Gulma Babandotan, Alelopati

\section{ABSTRACT}

This study aims to know the effectiveness and optimum concentration of mango leaf extract (Mangifera indica L.) which has phenol compounds that function as bioherbicides that can inhibit the growth of Babandotan weeds (Ageratum conyzoides). This research was carried out in the STIPAP greenhouse from April to May 2019. The method used was a NonFactorial Complete Randomized Design. Variables observed were weed height, weed root length, weed wet weight, and weed dry weight. The results of this study indicate that the $60 \%$ mango leaf extract allelochemical compound is an effective concentration and it is an alternative bioherbicide in controlling weed growth.

Keywords: Bioherbicide, Mortality, Babandotan Weed, Allelopathic

\section{PENDAHULUAN}

Babandotan (Ageratum conyzoides L.) merupakan gulma yang mengandung senyawa alelokimia (allelochemicals) yang sangat berbahaya di area perkebunan karena dapat menghambat pertumbuhan tanaman kelapa sawit. Penyebaran gulma ini sangat cepat karena dapat terbawa angin. Sehingga sangat perlu dilakukan pengendalian.
Pengendalian gulma menggunakan herbisida menimbulkan dampak negatif bagi lingkungan. Penggunaan herbisida jika dilakukan terus menerus dapat merusak lingkungan, meningkatkan resistensi gulma terhadap herbisida dan mengganggu kesehatan manusia sehingga diperlukan pengendalian alternatif. Daun mangga dapat dimanfaatkan sebagai pengendali gulma karena menghasilkan senyawa 
alelokimia yang dapat menghambat pertumbuhan gulma (Padmanaban dan Daniel, 2003). Seperti hasil penelitian (El-Rokiek et al., 2010) menyatakan bahwa ekstrak daun mangga dapat menghambat pertumbuhan rumput teki (Cyperus rotundus L.) pada konsentrasi 25\% karena ekstrak daun mangga mengandung senyawa alelopati golongan fenol antara lain ferulic, coumaric, benzoic, vanelic, chlorogenic, caffeic, hydroxybenzoic, dan cinnamic. Yulifrianti et al., 2015, menyatakan bahwa ekstrak daun mangga pada konsentrasi $35 \%$ dapat menghambat perkecambahan dan pertumbuhan gulma rumput Grinting (Cynodon dactylon. Penelitian ini bertujuan untuk mengetahui potensi alelopati ekstrak daun mangga (Mangifera indica L.) sebagai bioherbisida untuk pengendalian gulma $A$. conyzoides $\mathrm{L}$.

\section{METODE PENELITIAN}

\section{Tempat dan Waktu Penelitian}

Penelitian ini dilaksanakan di rumah kaca Sekolah Tinggi Ilmu Pertanian Agrobisnis Perkebunan (STIPAP). Waktu penelitian selama 2 bulan, dari bulan April sampai Mei 2019.

\section{Bahan dan Alat Penelitian}

Bahan-bahan yang digunakan pada penelitian ini adalah etanol $96 \%$, daun mangga harum manis dengan warna hijau ketuaan yang dipetik langsung dari pohon, benih biji gulma $A$. conyzoides L., tanah, polibag ukuran $10 \times 15 \mathrm{~cm}$ dan air. Alatalat yang digunakan adalah blender, goni, timbangan, parang, hand sprayer, cangkul, meteran, ember, dan gelas ukur.

\section{Rancangan Penelitian}

Penelitian ini menggunakan

Rancangan Acak Lengkap (RAL). Non Faktorial dengan perlakuan uji konsentrasi alelopati ekstrak daun mangga yaitu dengan konsentrasi $0 \%, 15 \%, 30 \%, 45 \%$, dan $60 \%$. Masing-masing perlakuan diulang sebanyak 5 kali sehingga diperoleh 25 sampel percobaan.

\section{Tahapan Penelitian}

\section{Persiapan Areal}

Membersihkan rumah kaca agar bersih dan rapi untuk mempermudah melakukan pengukuran membentuk setiap plot tanam. Membuat plot-plot tanam dengan tali plastik dengan ukuran $0,5 \mathrm{~m} \times 0,5 \mathrm{~m}$ dan jarak antar plot $0,5 \mathrm{~m}$. Dengan jumlah sampel sebanyak 125 gulma, dalam 1 plot terdapat 5 gulma, maka luas areal yang digunakan seluas $20,25 \mathrm{~m}^{2}$ (4,5 $\mathrm{m} \mathrm{x} \mathrm{4,5} \mathrm{m).}$ Media tanam terdiri dari tanah top soil yang sudah diayak, tanah di masukkan ke dalam polibag dengan ukuran $10 \times 15 \mathrm{~cm}$. Lalu didiamkan selama 3 hari agar tanah di dalam polibag dapat menyatu dan padat.

Perkecambahan Gulma.

Benih gulma Ageratum conyzoides L. sebanyak 5 biji disemaikan ke dalam setiap polibag. 1 plot terdapat 5 polibag. Pada penelitian terdapat 25 plot sehingga $25 \times 5$ $=125$ polibag. Penyiraman $2 \mathrm{x}$ sehari yaitu pada pagi hari dan sore hari hingga tanah basah. Gulma akan tumbuh setelah 10 hari, lalu dipilih 1 gulma yang memiliki ukuran yang sama pada masing-masing polibag.

\section{Pembuatan Ekstrak Daun Mangga Dengan Cara Maserasi.}

Daun mangga harum manis yang berwarna hijau tua yang diambil langsung dari pohon digunakan sebanyak $5 \mathrm{~kg}$ berat basah. Serasah daun mangga dicuci dengan air hingga bersih, lalu dikeringanginkan tanpa terkena cahaya matahari secara langsung selama 14 hari. Setelah daun kering lalu dipotong kecil-kecil menggunakan parang kemudian dihaluskan dengan blender. Setelah halus dikumpulkan dalam satu plastik ukuran $1 \mathrm{~kg}$. Bubuk daun mangga direndam (maserasi) dengan menggunakan pelarut etanol 96\% dalam gelas kimia selama 3 hari dan diaduk sekali dengan menggunakan sendok kayu. Rendaman tersebut disaring dengan menggunakan 
kertas saring dan corong ke dalam gelas kimia. Lakukan maserasi kembali dengan menggunakan etanol 96\% dari sisa ampas maserasi sebelumnya hingga ekstraksi yang dihasilkan jernih. Kemudian hasil ekstraksi tersebut dilakukan pemekatan larutan dengan menggunakan rotary evaporator.

\section{Aplikasi Bioherbisida}

Aplikasi bioherbisida dilakukan sekali selama penelitian. Bioherbisida dituangkan langsung ke tanah dalam polibag pada gulma yang berumur 2 minggu setelah tanam sebanyak $40 \mathrm{ml}$ dengan konsentrasi sesuai perlakuan. Aplikasi bioherbisida dilakukan pada pagi hari yaitu pukul 07.00 sampai 09.00 WIB.

\section{Pengamatan}

Peubah pertumbuhan gulma yang diamati meliputi tinggi gulma $(\mathrm{cm})$, panjang akar $(\mathrm{cm})$, berat basah $(\mathrm{g})$ dan berat kering $(\mathrm{g})$. Pengamatan dilakukan pada 5, 10, 15, dan 16 hari setelah aplikasi (HAS).

\section{III.HASIL DAN PEMBAHASAN}

\section{Tinggi Gulma Babandotan}

Hasil pengamatan tinggi gulma dengan pemberian alelopati ekstrak daun mangga pada waktu pengamatan ke-0, 5,10, dan 15 HSA dapat dilihat pada Tabel 1 .

Tabel 1. Rataan Pertumbuhan Tinggi Gulma (cm) Akibat Alelopati Ekstrak Daun Mangga

\begin{tabular}{lcccc}
\hline \multirow{3}{*}{ Perlakuan } & \multicolumn{4}{c}{ Tinggi Gulma (cm) } \\
\cline { 2 - 5 } & HSA & HSA & HSA & HSA \\
\hline A0 & 6,26 & 7,98 & 9,22 & $9,90 \mathrm{e}$ \\
A1 (15\%) & 5,11 & 6,32 & 6,90 & $6,88 \mathrm{~d}$ \\
A2 (30\%) & 4,80 & 5,24 & 5,85 & $4,59 \mathrm{c}$ \\
A3 (45\%) & 5,20 & 5,10 & 2,77 & $1,76 \mathrm{~b}$ \\
A4 (60\%) & 5,78 & 0,00 & 0,00 & $0,00 \mathrm{a}$ \\
\hline Keterangan: & Angka-angka yang diikuti oleh huruf yang \\
\multicolumn{5}{c}{ sama pada kolom yang sama berbeda tidak } \\
nyata dengan taraf nyata 5\% uji Duncan's \\
\multicolumn{4}{c}{ Multiple Range Test (DMRT) }
\end{tabular}

Berdasarkan Tabel 1 memperlihatkan bahwa perlakuan ekstrak alelopati daun mangga terhadap penekanan yang sangat berarti hingga pada taraf $(0.0 \mathrm{~cm})$ pertumbuhan gulma Babandotan pada perlakuan A4 yaitu pada konsentrasi $60 \%$ yang diaplikasi pada 5, 10 dan 15 hari setelah aplikasi (HSA). Kondisi ini jauh berbeda dengan pertumbuhan gulma Babandotan tanpa perlakuan (A0) yang menunjukkan trend pertumbuhan yang meningkat pada hari ke 15 tingginya mencapai 9,90 cm.

Pada penelitian ini pemberian 60\% ekstrak daun Mangga dengan senyawa alelokimia yang dimilikinya berpengaruh dalam menekan hingga ke taraf nol pertumbuhan gulma Babandotan. Senada dengan yang dikemukakan (Prasetya, 2018) bahwa ekstrak daun mangga dapat menekan pertumbuhan gulma, yaitu dengan cara menghambat pertambahan tinggi gulma secara signifikan. Hal ini disebabkan adanya kandungan senyawa alelokimia yaitu senyawa tanin yang menghambat pertumbuhan dan aktivitas hormon giberelin serta senyawa flavonoid yang dalam menekan aktivitas enzim dan pembelahan sel, yang selanjutnya berdampak pada pertumbuhan dan perkembangan gulma A.conyzoides L. (Pebriani, 2013 dalam Prasetya, 2018).

\section{Panjang Akar Gulma}

Hasil pengukuran pengaruh alelopati ekstrak daun mangga terhadap panjang akar gulma $A$. conyzoides L. Pada waktu pengamatan ke-15 HSA dapat dilihat pada Tabel 2.

Tabel 2.Rataan Panjang Akar Gulma (cm) Akibat Alelopati Ekstrak Daun Mangga Pada 15 HSA.

\begin{tabular}{cc}
\hline Perlakuan & Panjang Akar (cm) \\
\hline A0 & $15,30 \mathrm{e}$ \\
A1 $(15 \%)$ & $12,00 \mathrm{~d}$ \\
A2 $(30 \%)$ & $10,09 \mathrm{c}$ \\
A3 $(45 \%)$ & $3,64 \mathrm{~b}$ \\
A4 $(60 \%)$ & $0,00 \mathrm{a}$ \\
\hline
\end{tabular}

Keterangan: Angka-angka yang diikuti oleh huruf yang sama pada kolom yang sama berbeda tidak nyata dengan taraf nyata $5 \%$ uji Duncan's Multiple Range Test (DMRT) 
Tabel 2. Secara statistik menunjukan bahwa pemberian ekstrak daun Mangga gulma Babandotan mengalami hambatan untuk berkembang termasuk sistem perakarannya juga juga terganggu. Dapat dikatakan aplikasi ekstrak daun mangga $60 \%$ merupakan konsentrasi optimum yang efektif dalam menghambat pertumbuhan gulma Babandotan. (a)

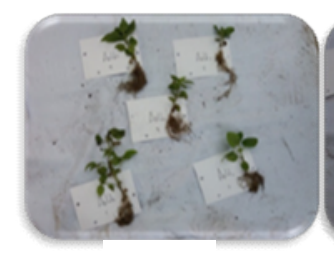

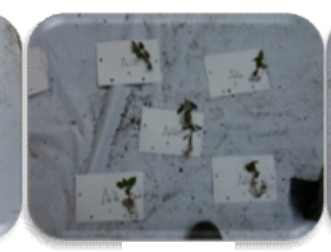

(b)

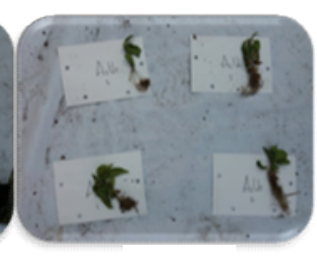

(c)

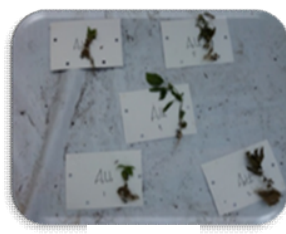

(d)

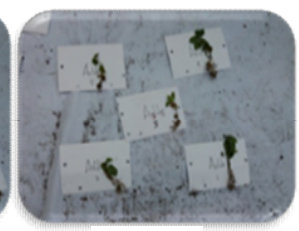

(e)
Gambar 1.Panjang Akar Gulma A. conyzoides L. Terhadap Pemberian Alelopati Ekstrak Daun Mangga Pada 15 HSA Untuk Setiap Perlakuan; (a) A0 (kontrol); (b) $15 \%$; (c) $30 \%$; (d) $45 \%$; dan (e) $60 \%$.

Pada gambar di atas dapat dilihat bahwa perlakuan A4 (60\%) berbeda nyata terhadap semua perlakuan. Hasil penelitian ini sesuai dengan (Tetelay, 2003 dalam Yulifrianti et al., 2015) menyatakan bahwa hambatan alelopati dapat berbentuk penghambatan pertumbuhan tanaman melalui gangguan sistem perakaran. Keberadaan senyawa fenol menyebabkan gangguan pada transportasi auksin dari pucuk ke akar dan gangguan sintesis sitokinin di bagian akar. Sitokinin diketahui berfungsi untuk pembelahan dan diferensiasi sel akar dan auksin merupakan senyawa yang memacu perpanjangan akar (Gardner et al., 1991 dalam Yulifrianti et al., 2015).

Senyawa alelopati yang diserap oleh akar tersebut menghambat pertumbuhan terutama pada bagian akar yang terkena langsung dengan ekstrak tersebut. (Sastroutomo, 1990 dalam Yulianfri et al., 2015) menyatakan bahwa alelokimia dapat diserap oleh tumbuhan di sekitarnya dalam bentuk uap, embun dan dapat pula masuk ke dalam tanah yang kemudian diserap oleh akar.

\section{Berat Basah Gulma}

Pengaruh pemberian alelopati ekstrak daun mangga terhadap berat basah gulma babandotan pada 15 hari setelah aplikasi ditunjukan pada Tabel 3 .

Tabel 3. Berat Basah Gulma A. conyzoides L. Akibat Alelopati Ekstrak Daun Mangga Pada 15 HSA

\begin{tabular}{lc}
\hline Perlakuan & Berat Basah $(\mathrm{g})$ \\
\hline A0 & $2,95 \mathrm{~d}$ \\
A1 $(15 \%)$ & $0,96 \mathrm{c}$ \\
A2 $(30 \%)$ & $0,97 \mathrm{c}$ \\
A3 $(45 \%)$ & $0,22 \mathrm{~b}$ \\
A4 $(60 \%)$ & $0,00 \mathrm{a}$ \\
\hline
\end{tabular}

Keterangan : Angka-angka yang diikuti oleh huruf yang sama pada kolom yang sama berbeda tidak nyata dengan taraf nyata 5\% ujiDuncan's Multiple Range Test (DMRT)

Tabel 3 memperlihatkan bahwa aplikasi 60\% ekstrak daun Mangga memberi efek penekanan terhadap pertumbuhan sehingga berat basah gulma menjadi rendah pada semua perlakuan. Tidak demikian halnya berat basah gulma A0 (Kontrol) tertinggi mencapat $2,95 \mathrm{~g}$.

Hal ini membuktikan bahwa pemberian alelopati ekstrak daun mangga dengan konsentrasi $60 \%$ efektif menurunkan berat basah gulma. Hal ini didukung oleh (Denada dan Kristanti, 2013 dalam Prasetya, 2018) yang menyatakan bahwa terdapat hasil yang signifikan terhadap berat basah gulma setelah diberi ekstrak daun mangga. Daun mangga ini mengandung senyawa alelokimia seperti flavonoid, tanin, steroid dan saponin. Pemberian ekstrak ini sangat efektif dalam menurunkan berat basah gulma Babandotan 
dikarenakan kandungan flavonoid yang dimilikinya berperan dalam menghambat proses pertumbuhan.

\section{Berat Kering Gulma}

Pengaruh pemberian alelopati ekstrak daun mangga terhadap berat kering gulma Babandotan pada 15 HSA dan dikeringkan dalam oven selama 1x24 jam ditunjukan pada Tabel 4

Tabel 4. Berat Kering (g) Gulma A.conyzoides Akibat Alelopati Ekstrak Daun Mangga Pada 15 HSA dan kering Ovenkan 1 x 24 Jam.

\begin{tabular}{lc}
\hline Perlakuan & Berat Kering (g) \\
\hline A0 & $0,77 \mathrm{e}$ \\
A1 $(15 \%)$ & $0,45 \mathrm{~d}$ \\
A2 $(30 \%)$ & $0,35 \mathrm{c}$ \\
A3 $(45 \%)$ & $0,10 \mathrm{~b}$ \\
A4 $(60 \%)$ & $0,00 \mathrm{a}$ \\
\hline Keterangan : Angka-angka yang diikuti oleh huruf yang \\
\multicolumn{2}{c}{ sama pada kolom yang sama berbeda tidak } \\
nyata dengan taraf nyata 5\% uji Duncan’s \\
Multiple Range Test (DMRT)
\end{tabular}

Tabel 4 menunjukkan bahwa oleh karena aplikasi 60\% ekstrak daun Mangga dapat menekan pertumbuhan gulma, sehingga begitu juga terhadap berat kering gulma. Sementara itu berat kering gulma tertinggi terdapat pada perlakuan A0 yaitu $0,77 \mathrm{~g}$. Rendahnya berat kering gulma pada taraf $(0,0 \mathrm{~g})$ ini berkaitan dengan rendahnya atau tidak adanya pertumbuhan $(0.0 \mathrm{~cm})$ gulma pada (Tabel 1).

Hasil penelitian ini sesuai dengan yang dikemukakan oleh (El-Rokiek et al., 2010) yang menyatakan bahwa alelopati ekstrak daun mangga memiliki efek penghambatan secara signifikan terhadap berat kering gulma Babandotan. Tingkat penghambatannya tergantung pada konsentrasi yang diaplikasi. Zat alelokimia yang terdapat dalam ekstrak daun mangga merupakan zat aktif yang efektif dalam mengendalikan pertumbuhan gulma yang diaplikasi pada hari 2, 10 dan 15 HSA.

\section{KESIMPULAN}

Alelopati ekstrak daun mangga (Mangifera indica L.) dapat digunakan sebagai bioherbisida dalam mengendalikan gulma Babandotan (Ageratum conyzoides). Efek alelokimia ekstrak daun mangga sebanyak $60 \%$ merupakan konsentrasi yang efektif dalam mengendalikan pertumbuhan gulma Babandotan.

\section{DAFTAR PUSTAKA}

Denada Visitia R. dan Kristanti Indah P. 2013. Studi Potensi Bioherbisida Ekstrak Daun Ketapang (Terminalia catappa) Terhadap Gulma Rumput Teki (Cyperus rotundus). Skripsi. Institut Eknologi Sepuluh November. Surabaya.

El-Rokiek, G., Kowthar, R., El-Masry., Rafet \& K. Nadia., Messiha. 2010. The Allelopathic Effect of Mango Leaves on the Growth \& Propagative Capacity of Purple Nutsedge (Cyperus rotundus L.). Journal American Research, vol. 6, no. 3, hal 151-159.

Padmanaban, B, \& M Daniel. 2003. Biology And Bionomics of Palm White Grub, Leucopholis burmeisteri. Indian Entom. vol. 65 no. 4, hal. 444-452.

Pebriani, Riza L., Mukarlina. 2013. Potensi Ekstrak Daun Sembung Rambat (Mikania micrantha H. B. K) Sebagai Bioherbisida Terhadap Gulma Maman Ungu (Cleome rutidosperma D.C) dan Rumput Bahia (Puspalum notatum Flugge). Protobiont. Vol 2(2) : 3238 .

Prasetya, D.N, Zulkifli, T.T. Handayani, Dan M.L. Lande. 2018. Efek Alelopati Ekstrak Air Daun Mangga (Mangifera indica L. var. 
Arumanis) Terhadap Pertumbuhan Rumput Teki (Cyperus rotundus L.). Jurnal Penelitian Pertanian Terapan, Volume 18 Nomor 02 . Universitas Lampung. Bandar Lampung.

Yulifrianti, E. Linda, R. Lovadi, I. 2015. Potensi Ekstrak Daun Mangga (Mangifera indica L.) Terhadap Pertumbuhan Gulma Rumput Ginting (Cynodon dactylon (L.)) Press. Jurnal Protobiont Volume 4 (1):46-51.Universitas Tanjungpura. Pontianak. 